\title{
OMISSÃO DE GRAFEMAS E CARACTERÍSTICAS DA SÍLABA NA ESCRITA INFANTIL
}

\section{Grapheme omissions and syllable constituents in children writing}

\author{
Aline Simão do Amaral (1), Maria Cláudia Camargo de Freitas (2), \\ Lourenço Chacon ${ }^{(3)}$, Luciana Lessa Rodrigues ${ }^{(4)}$
}

\section{RESUMO}

Objetivos: (1) verificar se as omissões ortográficas ocorriam preferencialmente na sílaba completa ou em partes da sílaba; (2) caracterizar a distribuição das omissões de acordo com a posição silábica do elemento omitido; (3) em ambas as possibilidades, verificar se as omissões ocorriam preferencialmente em posições acentuadas ou não-acentuadas de palavras. Métodos: dados extraídos de textos produzidos por pré-escolares de 5-6 anos. Resultados: quanto ao primeiro objetivo, omissões de partes de sílabas foram significativamente mais freqüentes $(p<0,0001)$. Quanto ao segundo objetivo, as omissões em coda silábica foram estatisticamente mais significativas $(p<0,0000)$. Com relação ao terceiro objetivo, as posições acentuadas se mostraram como relevantes apenas para as omissões de partes de sílaba $(p<0,0000)$. Conclusão: as omissões na escrita infantil têm caráter altamente complexo, fato que deve ser levado em consideração nos instrumentos de avaliação da escrita infantil.

DESCRITORES: Escrita Manual; Fonética; Aprendizagem

\section{INTRODUÇÃO}

A aquisição da linguagem permite às crianças ampliarem suas possibilidades de inserção e de participação nas diversas práticas sociais, sendo ainda um eixo básico para a educação infantil' ${ }^{1}$. Nesse contexto educacional, destaca-se a aquisição da escrita, "(...) processo mais específico no interior de um mais amplo, que é o processo de aquisição da linguagem"2.

(1) Fonoaudióloga formada pela Universidade Estadual Paulista (UNESP) - Marília/SP - Brasil;

(2) Fonoaudióloga do Centro de Orientação Médico-Psicopedagógica (COMPP) da Secretaria de Saúde do Distrito Federal (SES/DF); Doutoranda em Lingüística pela Universidade Estadual de Campinas (UNICAMP).

(3) Lingüista formado pela Universidade Estadual Paulista/ (UNESP, São José do Rio Preto; Professor do Curso de Fonoaudiologia da Universidade Estadual Paulista UNESP) - Marília/SP - Brasil; Doutor em Linguistica pela Universidade de Campinas (UNICAMP); Bolsista Pq/CNPq.

(4) Fonoaudióloga formada pela Universidade Estadual Paulista (UNESP) - Marília/SP - Brasil; Doutoranda em Linguistica pela Universidade de Campinas (UNICAMP); Bolsista CNPq.

Conflito de interesses: inexistente
Ao adquiri-la, as crianças mostram diversas dificuldades. Uma delas - foco do presente trabalho - são as omissões ortográficas. Neste estudo, as omissões serão vistas em relação à estrutura interna da sílaba, concebida como uma organização hierárquica de suas partes constitutivas ${ }^{3}$. No modelo hierárquico, a sílaba é uma estrutura na qual seus elementos se organizam hierarquicamente. Dois elementos, apenas, ligam-se ao nó (raiz) da sílaba: o ataque e a rima. Esta última, por sua vez, pode ser ramificada, já que, em seu interior, apresentamse estreitamente ligados um núcleo e uma coda. Veja-se, nessa perspectiva, o diagrama da estrutura silábica da palavra "porta":
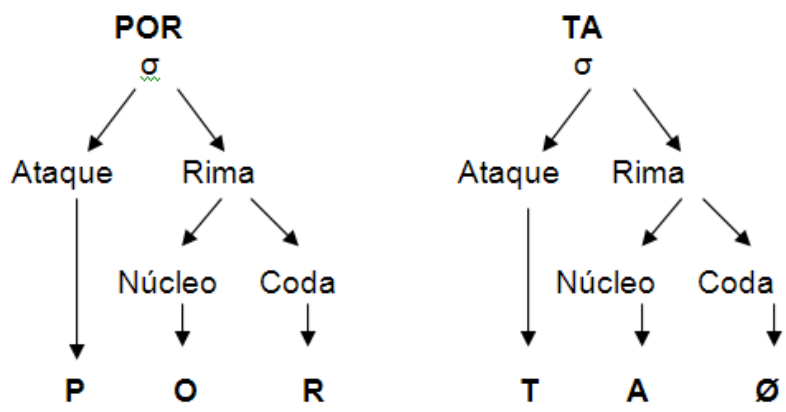
Uma das justificativas para a realização deste trabalho é a falta de estudos que especificamente têm como foco as omissões ortográficas. Nos raros trabalhos que as tematizam, elas são observadas sob a ótica do processamento da informação e relacionadas à estrutura morfológica da palavra ${ }^{4,5}$ - diferentemente da proposta deste artigo, que é relacioná-las não com a morfologia da palavra, mas com aspectos fonético-fonológicos da sílaba.

Há trabalhos que estudam os vínculos entre aspectos ortográficos e aspectos fonético-fonológicos de segmentos, de sílabas, de palavras ou de frases $^{6-28}$. Mas, embora se preocupem com essa relação, esses trabalhos investigam tanto questões de natureza ortográfica, quanto aspectos nãoconvencionais da escrita como aqueles relacionados à segmentação da palavra e à pontuação. Além disso, esses trabalhos voltam-se exclusivamente para a escrita de estudantes do Ensino Fundamental. Diferentemente desses estudos, a proposta deste artigo, além de investigar um tema que não foi especifica e exclusivamente tratado nos demais (as omissões ortográficas), se voltará para a escrita de estudantes do último ano da Educação Infantil, ano e etapa que imediatamente antecedem a primeira série do Ensino Fundamental.

Espera-se que este artigo possa fornecer subsídios para o trabalho que é desenvolvido com a aquisição da escrita na Fonoaudiologia. Visando analisar características fonético-fonológicas presentes na aquisição da escrita, mais especificamente, em omissões ortográficas, a investigação que resultou neste artigo foi orientada pelos seguintes objetivos:

(1) verificar se as omissões ortográficas ocorrem preferencialmente na sílaba como um todo ou em partes da sílaba;

(2) caracterizar a distribuição das omissões de acordo com a posição silábica do elemento omitido;

(3) em ambas as possibilidades, verificar se as omissões ocorrem preferencialmente em posições acentuadas ou não-acentuadas de palavras.

\section{MÉTODOS}

Para a realização deste estudo, foram utilizados textos infantis que vêm subsidiando investigações do Grupo de Pesquisa Estudos sobre a Linguagem (GPEL/CNPq). Os textos escritos fazem parte de um banco de dados elaborado por integrantes do Grupo acima referido. Desse banco, foram selecionados textos produzidos por crianças que, em 2007, freqüentavam o Pré III da Escola Municipal de Educação Infantil Raio de Sol na cidade de Marília/SP.
Os responsáveis por todas as crianças participantes da pesquisa permitiram, por escrito, sua participação a partir dos esclarecimentos contidos em Termo de Consentimento Livre e Esclarecido que Ihes foi apresentado.

Os dados foram coletados a partir de duas listas de palavras - denominadas Frutas e Animais. A primeira lista foi composta por um total de 24 nomes de frutas; já a segunda, por um total de nove nomes de animais.

A coleta dos dados foi realizada em três encontros de aproximadamente 30 minutos cada. A atividade proposta para a realização da coleta foi uma brincadeira semelhante a um bingo. No primeiro encontro, após explicação e contextualização da atividade, as fonoaudiólogas que coletaram os dados distribuíram uma folha de papel sulfite para cada aluno, na qual constavam 12 figuras de frutas. Seguem-se os nomes dessas frutas na ordem em que foram apresentadas, na folha, em duas colunas de seis figuras cada: pinha, romã, caju, goiaba, figo, morango, pêra, limão, ameixa, jabuticaba, abacaxi e mamão.

No sorteio, as figuras foram retiradas de um saco, inicialmente por uma das fonoaudiólogas e depois pelos alunos, não sendo revelado imediatamente o nome da fruta sorteada às crianças. Ao invés disso, era feita uma descrição para que as crianças descobrissem qual fruta havia sido sorteada. Assim que descobriam, as crianças escreviam o nome correspondente à fruta.

No segundo encontro, a atividade foi realizada da mesma maneira, com os 12 nomes de frutas restantes, a saber: caqui, melão, amora, uva, abacate, ponkan, laranja, carambola, banana, maçã, melancia, manga.

No terceiro encontro, realizou-se a coleta da lista Animais. Tal lista era composta por nove nomes de animais, cujas figuras eram dispostas em duas colunas, cinco à esquerda e quatro à direita: avestruz, urso, cisne, esquilo, porco, borboleta, boi, formiga e pardal. O procedimento adotado para a coleta dessa lista foi o mesmo da lista Frutas.

Para a realização deste artigo, foram retiradas do corpus as palavras melão, mamão, limão e banana, devido ao fato de essas palavras envolverem a ditongação do fonema /a/ (coda complexa) no caso das três primeiras, ou o fonema /a/ em contexto de nasalização fonética no caso da última palavra.

Em todo o material coletado foi considerado qualquer tipo de omissão, seja de sílaba completa ou de parte de sílaba, levando em conta a escrita convencional das palavras. Cabe ressaltar que a omissão de sílaba completa foi assim classificada quando a criança não colocou nenhum elemento (orto)gráfico que correspondesse às partes (ataque, núcleo e 
coda) de uma determinada sílaba, ou seja, quando não colocou nenhum grafema ou marca gráfica que pudesse ser classificada como parte dessa sílaba.

Foram classificadas como omissões de parte de sílaba os momentos de escrita em que se verificou a ausência de qualquer marca gráfica ou grafema que correspondesse a uma determinada parte da sílaba (ataque, núcleo ou coda).

Para o presente trabalho, é valido relembrar que não foi seu objetivo investigar se os sujeitos apresentavam algum distúrbio, atraso ou qualquer alteração de linguagem, nem de ordem falada nem de ordem escrita.

Inicialmente, as propostas realizadas pelas crianças foram digitalizadas. Em seguida, foram extraídos todos os dados que continham algum tipo de omissão, (de parte de sílaba e da sílaba gráfica como um todo).

Para a análise dos dados, comparou-se a escrita tal como produzida pelas crianças com a escrita alvo, ou seja, a escrita tal como deveria ser feita de acordo com as convenções ortográficas. Em outras palavras, comparou-se, por exemplo, a escrita mecia com a escrita convencional do nome dessa fruta (melancia). Assim, chegou-se ao resultado de omissão total da sílaba lan. No caso de omissões de partes de sílaba, uma escrita como, por exemplo, a de inha para pinha indicou omissão do ataque da primeira sílaba, a saber, $p$.

Para a busca de possíveis interpretações das omissões, como se verá mais adiante, foram utilizados subsídios extraídos de estudos fonológicos e fonéticos sobre a síllaba ${ }^{3,29-33}$.

A realização da pesquisa foi aprovada pelo Comitê de Ética em Pesquisa da FFC/Unesp, tendo sida registrada sob o no 3431/2008.

Foi feito um tratamento estatístico dos dados com o uso do software Statistica (versão 7.0). Em relação ao primeiro objetivo da pesquisa, foi utilizado o teste não-paramétrico Wilcoxon, adotando como variáveis dependentes (1) omissão de sílaba como um todo e (2) omissão de partes de sílaba. Já com respeito ao segundo objetivo, foi utilizado o teste não-paramétrico ANOVA de Friedman, considerando como variáveis dependentes cada parte da sílaba: ataque; núcleo; e coda. Por fim, quanto ao terceiro objetivo, mais uma vez, foi utilizado o teste não-paramétrico Wilcoxon, especificando como variáveis dependentes a presença ou não de acento e como variável independente a natureza da omissão (de sílaba como um todo ou de parte de sílaba). Foram considerados como estatisticamente significativos os resultados com valores de $p$ inferiores a $0,05(p<0,05)$ e como marginais os resultados com valores de $p$ entre 0,05 e 0,1 $(0,05<p<0,1)$.

\section{RESULTADOS}

Para a exposição de resultados, serão levados em consideração os objetivos que nortearam o desenvolvimento da pesquisa. Em outras palavras, os resultados serão apresentados de acordo com cada um desses objetivos.

O primeiro deles foi verificar se as omissões ortográficas ocorriam preferencialmente na sílaba como um todo ou em partes da sílaba. Para atingilo, foram levantadas as possibilidades de registro de sílabas, bem como dos elementos (ataque, núcleo e coda) no interior de cada sílaba nas palavras analisadas. Chegou-se a um total de 1410 sílabas e 3042 elementos de possibilidades de registro ortográfico.

Dentre as 1410 possibilidades de registro de sílabas, 58 sílabas completas foram omitidas pelo conjunto dos sujeitos e, dentre as 3042 possibilidades de registro de elementos, 321 deles foram omitidos, tal como exposto na Figura 1:

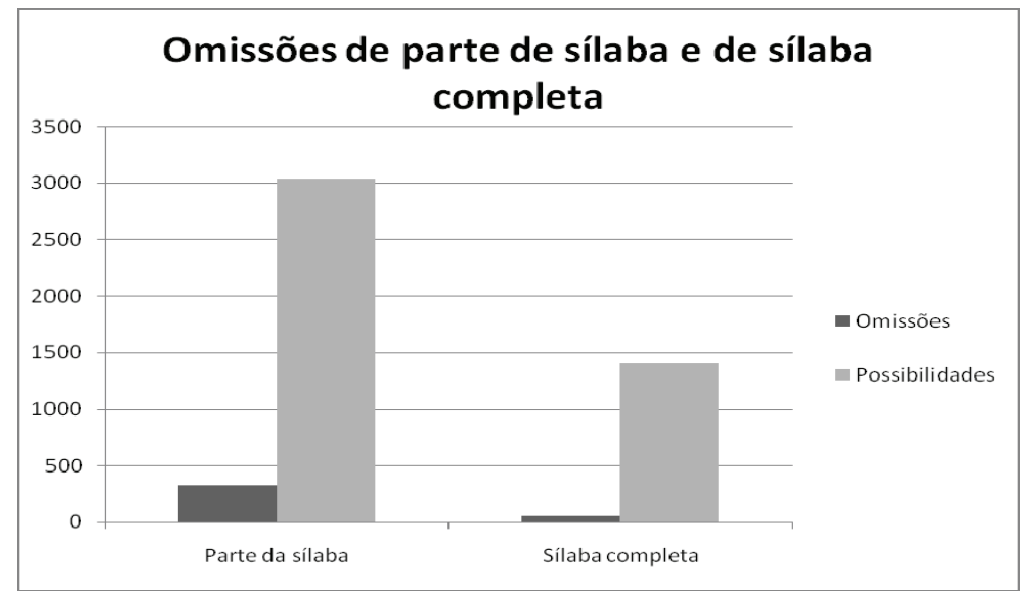

Figura 1 - Distribuição do total de possibilidades de registro comparado com o total de omissões. 
Houve, portanto, uma prevalência de omissões de parte de sílaba, já que as crianças omitiram $10,55 \%$ de parte de sílaba e $4,11 \%$ de sílaba completa. Essa prevalência mostrou-se como estatisticamente significativa: $Z=3,80, p<0,0001$. Como exemplo desses dois tipos de omissões, podemos citar:

(a) de sílaba completa:

- omissão de "GO", $3^{\text {a }}$ sílaba da palavra MORANGO

\section{MORAN}

- omissão de "LAN", 2ª sílaba da palavra MELANCIA

\section{MECIA}

- omissão de “BO”, 2a ${ }^{a}$ sílaba da palavra BORBOLETA

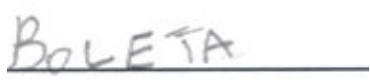

(b) de parte de sílaba:

- omissão do núcleo "A" - da $2^{2}$ sílaba - e do núcleo "A" - da 3" sílaba da palavra ABACAXI

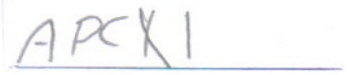

- omissão do ataque “P”, da 1a sílaba de PINHA

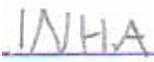

- omissão da coda "L", da $2^{a}$ sílaba de PARDAL

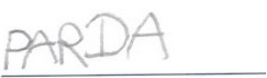

Após essa etapa, a análise voltou-se para as questões relativas ao segundo objetivo que a orienta: caracterizar a distribuição das omissões em partes de sílaba de acordo com a posição silábica do elemento omitido. Investigou-se, dessa forma, se a parte omitida consistia em ataque, núcleo ou coda. Os resultados constam da Figura 2:

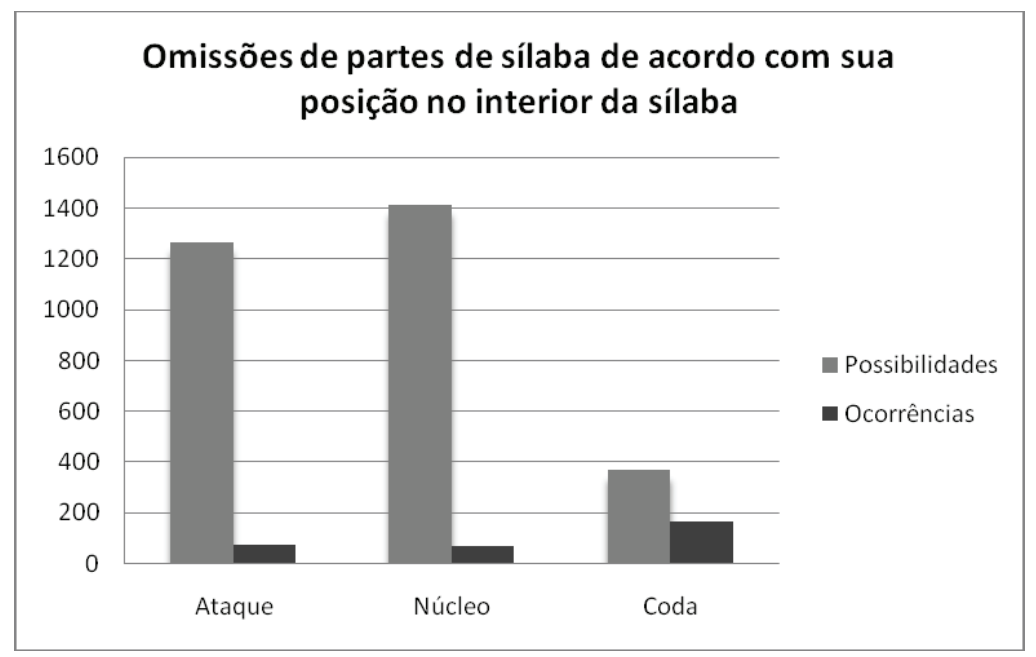

Figura 2 - Omissões de ataque, núcleo e coda.

É possível observar que, na posição de coda, houve maior concentração de omissões, num total de $46,20 \%$, e que, nas posições de ataque e de núcleo, a quantidade de omissões foi próxima, de $6,49 \%$ e $4,89 \%$, respectivamente - lembrando-se de que essas porcentagens se referem à porcentagem de omissões em relação ao conjunto de possibilidades de ocorrência para cada posição na sílaba - ataque, núcleo e coda. Essa diferença entre coda, por um lado, e ataque e núcleo, por outro lado, mostrou-se como estatisticamente significativa: $F_{21,2}=32,666, p<0,0000$.

Seguem exemplos de omissões de parte de sílaba:

(a) de ataque:

- Omissão de "QU" na $2^{\text {a }}$ sílaba da palavra CAQUI

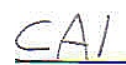


(b) de núcleo:

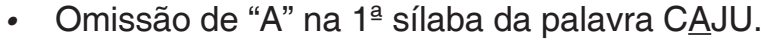

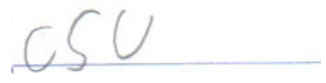

(c) Ode coda:

- Omissão de "N" na 1a sílaba da palavra PONKKAN.

POCAN
No tocante ao terceiro objetivo específico,verificou-se - tanto em sílabas completas como em parte de sílaba - a possibilidade de as omissões variarem de acordo com a tonicidade da sílaba na palavra.

Verificou-se, inicialmente, se as omissões de sílaba completa ocorreram preferencialmente em posições acentuadas ou não-acentuadas das palavras. A Figura 3 ilustra os resultados dessa verificação:

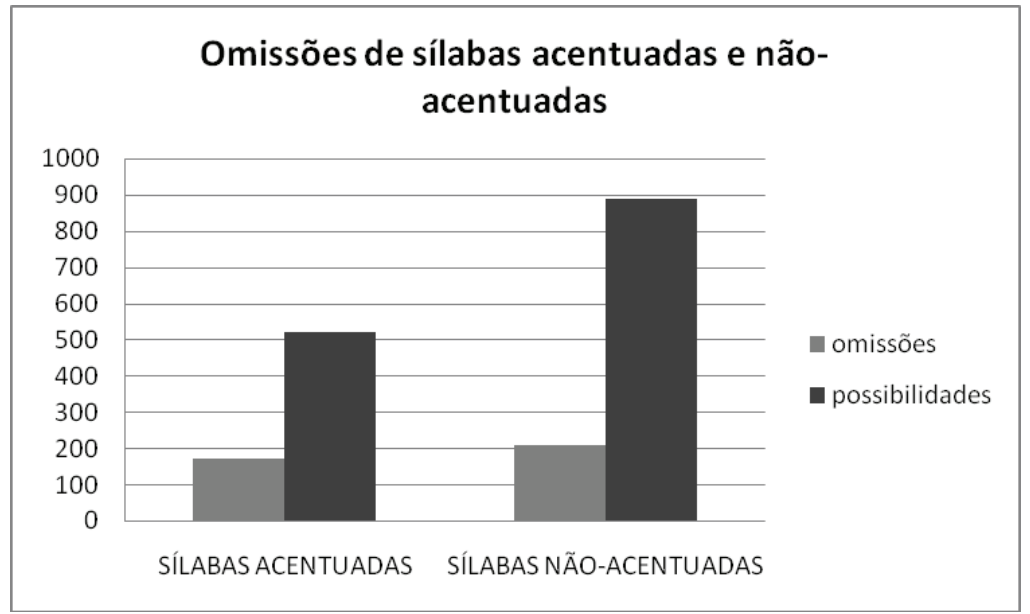

Figura 3 - Total de omissões de sílaba completa de acordo com a tonicidade da sílaba na palavra.

Foi observado, quanto às omissões de sílabas completas, que as sílabas acentuadas foram omitidas em um percentual pouco acima $(32,63 \%)$ daquele verificado nas não-acentuadas - prétônicas e pós-tônicas - (23,51\%). Essa diferença não se mostrou como estatisticamente significativa: $Z=1,13, p=0,25$.

Seguem-se exemplos desse tipo de omissões:

(a) de sílaba completa em posição acentuada:

- Omissão da sílaba acentuada "RAN" na palavra LARANJA

\section{LAGA}

(b) de sílaba completa em posição não-acentuada:

- Omissão da sílaba não-acentuada "BA" na palavra JABUTICABA

JBUTICA

Da mesma forma, quanto às omissões de parte de sílaba, foi verificado se o elemento omitido figurava em sílaba acentuada ou não-acentuada da palavra. A Figura 4 ilustra os resultados dessa verificação: 


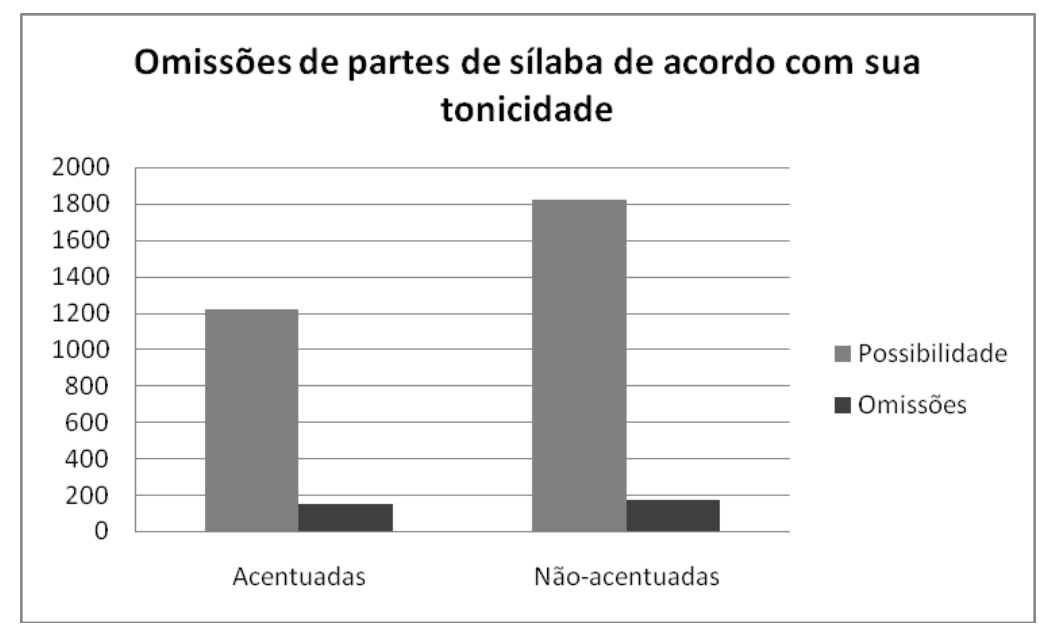

Figura 4 - Total de omissões de partes de sílaba de acordo com a tonicidade da sílaba na palavra.

Em relação às omissões de partes de sílaba, as omissões de elementos presentes em sílabas acentuadas obtiveram freqüência pouco maior (152 dentre 1218 possibilidades $=12,48 \%$ ) do que as omissões de elementos de sílabas não-acentuadas (169 dentre 1824 possibilidades = 9,27\%). Embora percentualmente não tão distante, essa diferença mostrou-se, no entanto, bastante robusta em termos de significância estatística: $Z=3,91, p<0,0000$.

Seguem-se exemplos de omissões de partes de sílaba em posições acentuadas e não-acentuadas:

(a) de ataque em posições acentuada e não-acentuada:

- omissão de $/ \mathrm{m} /$ em sílaba acentuada da palavra AMORA

\section{AORA}

- omissão de /g/ em sílaba não-acentuada da

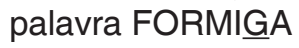

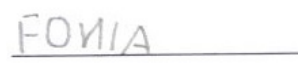

(b) de núcleo em posições acentuada e não-acentuada:

- omissão de /e/ em sílaba acentuada da palavra PÊRA

- omissão de /e/ em sílaba não-acentuada da palavra AVEESTRUZ (c) de coda em posições acentuada e não-acentuada:

- omissão de /N/ em sílaba acentuada da palavra MANGA

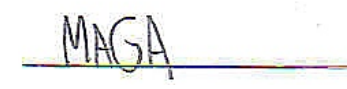

- omissão de /S/ em sílaba não-acentuada da palavra ESQUILO

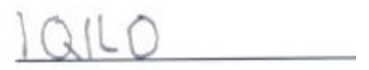

Sintetizando os resultados de acordo com o primeiro objetivo (verificar se as omissões ortográficas ocorriam preferencialmente na sílaba como um todo ou em partes da sílaba), foi detectada prevalência estatisticamente significativa de omissões de parte de sílaba em relação à de sílabas completas.

Em relação ao segundo objetivo, buscou-se investigar que elemento era mais omitido dentro da sílaba: ataque, núcleo ou coda. Verificou-se que as omissões na posição de coda mostraram-se estatisticamente significativas quanto comparadas às omissões nas duas outras posições (ataque e núcleo).

Por fim, em relação ao terceiro objetivo (relacionar as omissões à tonicidade da sílaba na palavra), não houve diferença estatisticamente significativa quando se tratava de omissões de sílaba como um todo. Houve, no entanto, diferença estatisticamente significativa em omissões de partes de sílaba, com a tendência de maior ocorrência dessas omissões em sílabas acentuadas. 


\section{DISCUSSÃO}

Inicialmente, pôde-se observar prevalência de omissões de partes de sílabas em relação a omissões de sílabas completas $(p<0,0001)$. Possivelmente, essa prevalência se deva à ênfase posta nesse constituinte pelas práticas de letramento desenvolvidas em contexto escolar durante as atividades de alfabetização. Com efeito, além de cartazes nas salas de aula com famílias silábicas, é prática recorrente dos alfabetizadores silabar oralmente, em atividades pedagógicas, as palavras para as crianças. Essa ênfase certamente favorece a sensibilidade das crianças a esse constituinte, fazendo com que elas tentem registrá-lo de algum modo em sua escrita com pelo menos um grafema. Desse modo, de um ponto de vista fonológico, pode-se supor que essas práticas contribuem para a construção de representações sobre a sílaba enquanto unidade da língua - já que as crianças tendem a omiti-la significativamente menos do que omitem suas partes. Também de um ponto de vista fonológico, os resultados indicam que a representação das partes menores da sílaba, especialmente da coda, parece se dar em uma etapa posterior à da representação da unidade sílaba, sobretudo porque supõe a representação de ramificações dessa unidade.

Com relação à prevalência de omissões em coda $(p<0,0000)$, é necessário, primeiramente, lembrar que "(...) O esforço muscular que gera as sílabas pode ser caracterizado como um movimento de força que se intensifica e se reduz em cada sílaba." ${ }^{33}$. Isso porque, de um ponto de vista fonético, toda sílaba supõe, em sua produção: (1) um momento de intensificação da força muscular que (2) atinge seu limite máximo e (3) passa a um momento de redução. Esses três momentos correspondem, respectivamente, às posições fonológicas de ataque, núcleo e coda.

A significativa maior ocorrência de omissões na posição de coda explica-se, pois, em termos fonéticos, pelo fato de que a posição de coda corresponde a momentos não-favorecidos perceptualmente ${ }^{32}$, em razão de coincidirem com os momentos de decréscimo de energia. Adicionalmente, de um ponto de vista fonológico, deve-se destacar que a posição estrutural da coda encontra-se numa ramificação de uma das partes da sílaba (a rima), complexidade que poderia favorecer seu apagamento na escrita, tal como, em grande medida, é verificado também na fala infantil. As práticas pedagógicas ligadas à alfabetização de certo modo também levariam a essa significativa omissão, já que as famílias silábicas são exaustivamente apresentadas às crianças sob a forma CV, descartando, pelo menos no início da alfabetização, outros padrões de estruturação silábica na escrita.

Um resultado importante a ser mencionado é o da ausência de significância nas omissões no ataque (momento de intensificação de força na produção da sílaba) em relação às omissões no núcleo (centro da atividade motora e acústica da sílaba). Essa ausência provavelmente se explique, uma vez mais, em função do acesso da criança à informação visual das famílias silábicas, que reforçam uma constituição binária da sílaba ortográfica - uma posição correspondente a uma consoante; e outra posição correspondente a uma vogal. Destaque-se, no entanto, um fato interessante: das 69 omissões de núcleo, 18 ocorrências $(26,09 \%)$ correspondem a palavras nas quais o nome do grafema inclui a vogal da sílaba, como, por exemplo, no registro avstrus realizado pela criança, correspondente à palavra avestruz. Nesse caso, a criança pode estar usando o grafema " $v$ " para representar tanto " $v$ " quanto "e" da palavra avestruz. Dados como esse indicam, portanto, uma possível hipótese construída pela criança para o registro do núcleo da sílaba, embora ainda não correspondam ao seu registro convencional. Ressalte-se que essa interpretação corrobora as seguintes considerações:

Algumas omissões podem ser causadas por uma espécie de confusão que a criança faz entre o 'som' que a letra escreve e o 'nome' da letra. Por exemplo, algumas vezes encontramos palavras como 'tlefone' (telefone) ou 'pgar' (pegar) escritas sem a vogal 'e' uma vez que a criança acredita que, se escreveu a letra ' $t$ ', ou a letra ' $p$ ', elas já contêm o 'e', em razão do próprio nome delas: 'te' e 'pe'. ${ }^{34}$

Finalmente, quanto à relação entre omissões e acento, no que diz respeito às omissões de sílabas como um todo, a presença/ausência de acento não se mostrou estatisticamente significativa $(p=0,25)$, diferentemente do que ocorreu nas omissões de partes de sílaba $(p<0,0000)$.

Em relação às omissões de sílaba como um todo, a não-significância mostra que não é porque as sílabas acentuadas concentram maior intensidade e duração do que as não-acentuadas que serão menos omitidas, como se poderia prever tendo como base uma explicação predominantemente fonética. Assim, essa não-significância parece decorrer de como os alfabetizadores, em suas práticas pedagógicas, separam as palavras em sílabas para as crianças: ao enfatizarem sua quantidade no interior de uma palavra, eles o fazem de modo a minimizarem o contraste entre a sílaba acentuada e as não-acentuadas da palavra. Detectam-se, portanto, indícios do caráter heterogêneo da escrita, já que os resultados sugerem que 
as crianças não se orientam apenas por características presentes na fala quando escrevem, mas trazem, também, para sua escrita conhecimentos decorrentes de sua inserção histórica em práticas de letramento. Em outras palavras, o produto escrito das crianças se ancora não apenas no que falam e o no que ouvem, mas, também, no que escrevem e lêem - fato que demonstra a importância que (também) os aspectos visuais da escrita têm para as crianças.

Essa hipótese se confirma no que diz respeito às omissões de partes de sílabas, já que foram estatisticamente significativas as omissões em posições acentuadas, quando comparadas às omissões em posições não-acentuadas. Contrariando a suposição de que a criança se orientaria predominantemente pelos aspectos fonético-fonológicos em sua escrita inicial, a significativa maior ocorrência de omissões justamente em partes de sílabas acentuadas de palavras sugere, uma vez mais, que as crianças oscilam em relação ao que thes serve de base para a escrita: ora se sustentam em informações que extraem de como as palavras são pronunciadas, ora em informações que extraem de como as palavras são grafadas - sem que, necessariamente, os aspectos fonético-fonológicos das palavras tenham prevalência sobre os aspectos visuais.

\section{CONCLUSÃO}

Este trabalho teve como proposta investigar como se caracterizam as omissões ortográficas na escrita de pré-escolares - uma vez que, pelo menos no município em que vivem as crianças deste estudo, desde a educação infantil, elas entram em contato direto com a alfabetização. Desse modo, não só os dados de escrita do ensino fundamental merecem atenção para se abordarem as hipóteses sobre a aquisição da escrita (como ocorre com a maioria dos estudos mencionados neste trabalho), mas, também, os dados de escrita produzidos no contexto da educação infantil.

Os resultados indicam que as omissões na escrita infantil têm caráter altamente complexo, uma vez que não apenas mostram vínculos com características orais da sílaba, como, também, dependem de fatos privilegiados nas práticas de letramento desenvolvidas em contexto escolar.

Como desdobramentos desses resultados, esta investigação sugere que as avaliações da atividade de escrita em crianças de educação infantil levem em consideração o fato de que as crianças (pelo menos as que constituíram a amostra desta pesquisa) analisam antes a sílaba como unidade da língua (e da escrita) do que suas partes - o que significa dizer que não se deveria avaliar com o mesmo peso as omissões de sílabas como um todo e as omissões de partes de sílabas, nem mesmo as omissões de diferentes partes da sílabas.

Assim, este trabalho, teve também o propósito de chamar a atenção para a complexidade da aquisição da escrita e, ainda, para quão importante é desenvolver estudos com dados de crianças da educação infantil. Como se pôde verificar, já nesta época as crianças dão indícios de quais são as posições mais facilmente registráveis da sílaba e de quais são aquelas naturalmente mais propensas a serem omitidas. Em outras palavras, este trabalho aponta para a a importância de se criarem instrumentos de avaliação da escrita que levem esses fatos em consideração.

\section{AGRADECIMENTOS}

Para Larissa Cristina Berti, pela leitura atenta e crítica deste trabalho, bem como pela substancial ajuda com a análise estatística dos dados.

\section{ABSTRACT}

Purpose: (1) verify if orthographic omissions occurred mainly in the whole syllable or in syllable parts; (2) characterize the distribution of these omissions according to syllabic parts of the omitted graphemes; (3) in both possibilities, verify if such omissions mainly occurred in stressed or unstressed word positions. Methods: data collected from texts produced by 5 to 6 -year-old Brazilian pre-school children. Results: as for (1), omissions in syllable parts occurred significantly more often $(p<0,0001)$. In (2), omissions in syllabic coda were statistically more significant $(p<0.0000)$. While in (3), the stressed positions were relevant only to omissions concerning syllable parts $(p<0.0000)$. Conclusion: the omissions in children writing are highly complex. So that this complexity should be taken into account in writing evaluation procedures.

KEYWORDS: Handwriting; Phonetics; Learning 


\section{REFERÊNCIAS}

1. Brasil Ministério da Educação e do Desporto. Secretaria de Educação Fundamental. Referencial curricular nacional para a educação infantil/ Ministério da Educação e do Desporto, Secretaria de Educação Fundamental. - Brasília: MEC/SEF, 1998. 3v.: il.

2. Abaurre MBM, Fiad RS, Mayrink-Sabinson MLT Cenas de aquisição da escrita. Campinas: Mercado das Letras, 1997.

03. Selkirk EO The syllable. In: Hulst FV \& Smith N (orgs). The structure of phonological representations. Dordrecht Foris, 1982.

4. Sterling $\mathrm{CM}$ Spelling errors in context. British Journal of Psychology, 1983; 74: 353-64.

5. Mota M, Moussatch AH, Castro CR, Moura, MLS, D'angelis T Erros de escrita no contexto: uma análise na abordagem do processamento da informação. Psicol Reflex Crit, Porto Alegre, 2000; 13(1):1-6.

6. Apel K The Acquisition of Mental Orthographic Representations for Reading and Spelling Development. Communication Disorders Quarterly, 2009; 31(1): 42-52.

7. Berberian AP et al. Análise de ocorrências ortográficas não convencionais produzidas por alunos do Ensino Fundamental. Tuiuti: Ciência e Cultura, 2008; 39: 23-39.

8. Brondani AR, Assencio-Ferreira VJ, Zorzi JL A incidência de trocas surdas/sonoras na escrita de crianças com e sem história de alteração de linguagem. Rev CEFAC, 2002; 4: 105-10.

9. Capellini SA, Conrado TLBC Desempenho de escolares com e sem dificuldades de aprendizagem de ensino particular em habilidade fonológica, nomeação rápida, leitura e escrita. Rev CEFAC, 2009; 11(2): 183-93.

10. Capristano CC Segmentação na escrita infantil. São Paulo: Martins Fontes, 2007.

11. Cardoso-Martins C, Batista ACE O conhecimento do nome das letras e o desenvolvimento da escrita: evidência de crianças falantes do português. Psicol Reflex Crit, 2005; 18(3): 330-6.

12. Castles A, Davis C, Cavalot P, Forster K Tracking the acquisition of orthographic skills in developing readers: masked priming effects. Journal of Experimental Child Psychology, July 2007; 97(3): 165-82.

13. Cavalcante TCF Argumentação e apropriação ortográfica em crianças com distúrbio de leituraescrita. Linguagem \& Ensino, jul./dez.2007; 10(2): 503-25.

14. Cervera JF, Ygual A Evaluación e intervención en niños con trastornos fonológicos y riesgo de dificultad de aprendizaje de la lectura y escritura. Cuadernos de Audición y Lenguaje, 2001; (1): 1-41.
15. Chacon $L$ Hipersegmentações na escrita infantil: entrelaçamentos de práticas de oralidade e de letramento. Estudos Lingüísticos, Campinas (SP), 2005; 34: 77-86.

16. Chacon $L$ Para além de vínculos diretos entre características fonético-segmentais e ortográficas na escrita infantil. Revista de Estudos da Linguagem, 2008; 16: 215-30.

17. Cunha APN, Miranda ARM A influência da hierarquia prosódica em hipossegmentações da escrita de crianças de séries iniciais. ReVEL, 2007; 5: 1-19.

18. Cunha APN, Miranda ARM A hipo e a hipersegmentação em dados de aqusição de escrita: a influência da prosódica. Alfa (IBILCE/ UNESP), 2009; 53: 123-48.

19. Davis C, Bryant $P$ Causal connections in the acquisition of an ortographic rule: a testo $f$ Uta Frith's developmental hypothesis. Journal of child psychology and psychiatry, 2006; 47(8): 849-56.

20. Dias RS, Ávila CRB Uso e conhecimento ortográfico no transtorno específico da leitura. Rev Soc Bras Fonoaudiol, 2008; 13(4): 381-90.

21. Diuk B, Borzone AM, Abchi VS, Ferroni M La adquisición de conocimiento ortográfico en niños de 1er a 3er año de Educación Básica. PSYKHE, 2009, 18(1): 61-71.

22. Fernandes S, Ventura $P$, Querido L, Morais $\mathrm{J}$. Reading and spelling acquisition in European Portuguese: a preliminary study. Read Writ, 2008, 21: 805-21.

23. Lemes JP, Goldfeld, M Análise da ortografia de crianças usuárias de implante coclear. Rev Soc Bras Fonoaudiol, 2008; 13(3): 179-89.

24. Martens VEG, Jong PF The effect of visual word features on the acquisition of orthographic knowledge. Journal of Experimental Child Psychology, april 2006; 93(4): 337-56.

25. Rincón L, Hederich C Relaciones entre aprendizaje inicial de la lengua escrita, métodos de enseñanza y estilo cognitive. Folios, 2008; 28:51-63. 26. Tenani LE Notas sobre a relação entre constituintes prosódicos e ortografia. Revista de Estudos da Linguagem, 2008; 16: 231-45.

27. Zorzi JL, Ciasca SM Caracterização dos erros ortográficos em crianças com transtornos de aprendizagem. Rev CEFAC, São Paulo, 2008; 10(3): 321-31

28. Zuanetti PA, Corrêa-Schnek AP, Manfredi AKS Comparação dos erros ortográficos de alunos com desempenho inferior em escrita e alunos com desempenho médio nesta habilidade. Rev Soc Bras Fonoaudiol, 2008; 13(3): 240-5.

29. Stetson RH Motor Phonetics, $2^{\mathrm{a}}$ ed. Amsterdam: NL, North-Holland Pub. Co., 1951. 
30. Abercrombie D Elements of general phonetics. Edinburgh: Edinburgh University Press, 1967.

31. Camara Jr JM Estrutura da língua portuguesa. Petrópolis: Vozes, 1970.

32. Jakobson R (1985) Fonema e fonologia. In: Saussure $\mathrm{F}$ et al. Textos selecionados. 3. ed. São Paulo: Abril Cultural (Coleção "Os pensadores").
33. Cagliari LC Elementos de fonética do português brasileiro. São Paulo: Paulistana, 2007.

34. Zorzi JL, Capellini, SA Dislexia e outros distúrbios da leitura-escrita: letras desafiando a aprendizagem. 2 ed. São José dos Campos: Pulso, 2009.

http://dx.doi.org/10.1590/S1516-18462011005000007

RECEBIDO EM: 21/06/2010

ACEITO EM: 20/09/2010

Endereço para correspondência:

Lourenço Chacon

Departamento de Fonoaudiologia - Unesp

Av. Hygino Muzzi Filho, 737

Marília - SP

CEP: $17525-900$

E-mail: chacon@terra.com.br 